\title{
Posidonia oceanica and Cymodocea nodosa seedling tolerance to wave exposure
}

\author{
Eduardo Infantes, $,{ }^{a},{ }^{*}$ Alejandro Orfila, ${ }^{a}$ Tjeerd J. Bouma, ${ }^{b}$ Gonzalo Simarro, ${ }^{c}$ and Jorge Terrados ${ }^{a}$ \\ a Instituto Mediterráneo de Estudios Avanzados (Consejo Superior de Investigaciones Científicas-Universidad de la Islas Baleares), \\ Esporles, Spain \\ b Nederlands Instituut voor Ecologie, Centrum voor Estuariene en Mariene Ecologie, Yerseke, the Netherlands \\ c Instituto de Ciencias del Mar (Consejo Superior de Investigaciones Científicas), Barcelona, Spain
}

\begin{abstract}
We studied the role of hydrodynamics in the establishment of sea grass seedlings for two Mediterranean sea grass species, Posidonia oceanica and Cymodocea nodosa, by combining flume and field studies. Flume measurements under both unidirectional and oscillatory flow showed that $P$. oceanica seedlings experienced higher drag forces than $C$. nodosa, which could be related to the larger total leaf area. Drag coefficients were between 0.01 and 0.1 for Reynolds numbers of $10^{3}$ and $10^{5}$. As a result, $P$. oceanica seedlings required $40-50 \%$ of root length anchored to the sediment before being dislodged, whereas $C$. nodosa required $\approx 20 \%$. To validate the flume results, seedling survival in sandy beds was evaluated for two depths (12 and $18 \mathrm{~m})$ at two field locations. To calculate near-bottom orbital velocities at the planting sites, deep-water waves were propagated to shallow water using a numerical model. Our results showed that $P$. oceanica seedlings experienced high losses after the first autumn storms when near-bottom orbital velocities exceeded $18 \mathrm{~cm} \mathrm{~s}^{-1}$. The loss of $C$. nodosa seedlings was much lower and some seedlings survived velocities as high as $39 \mathrm{~cm} \mathrm{~s}^{-1}$. Thus, flume and field results are consistent in explaining relative higher losses of $P$. oceanica seedlings than for $C$. nodosa.
\end{abstract}

Aquatic vegetation like sea grass plays an important role in coastal environments by providing many ecosystem services (Costanza et al. 1997), such as, e.g., preventing shoreline erosion by wave attenuation within sea grass beds (Koch et al. 2009). Sea grass growth and development is, however, highly dependent on physical, chemical, and ecological conditions such as hydrodynamics, light availability, substratum type, organic matter in the sediment, and herbivory (Koch 2001; Short et al. 2002).

Sea grass seedlings are the elements that form new meadows and their survival in nature contributes to sea grass population dynamics. Waves and currents can strongly influence the spatial distribution of meadows (Frederiksen et al. 2004; Infantes et al. 2009), suggesting that hydrodynamics is highly important for seedling establishment. Measurements showing higher seedling survival rates at deeper locations suggest the same (Piazzi et al. 1999). Moreover, it has been shown that hydrodynamics can directly affect the survival of sea grass seedling transplants (van Katwijk and Hermus 2000; Rivers et al. 2011). The effect of waves and currents on seedling establishment is expected to be through sediment movement, as this can cause burial or dislodgment of small sea grass plants.

Sea grass capacity to withstand sediment burial is strongly dependent on size and morphology (IdestamAlmquist and Kautsky 1995; Cabaço et al. 2008). The effect of sediment erosion on survival could be determined by the root capacity to remain anchored to the substratum (Madsen et al. 2001). Hence, seedlings may be expected to be highly vulnerable to sediment movement compared with adult sea grasses, as seedling roots will penetrate less deeply into the sediment. Although the effect of sediment

\footnotetext{
* Corresponding author: eduardo.infantes@uib.es
}

burial on sea grasses has been reviewed (Cabaço et al. 2008), to our knowledge, little work has been devoted to the effect of sediment dynamics, in particular the effect of sediment erosion and root-anchoring capacity on seedling survival. We address this question for the two most common sea grass species in the Mediterranean Sea (Green and Short 2003) that both strongly declined during the 20th century (Boudouresque et al. 2009): Posidonia oceanica and Cymodocea nodosa.

Both species have morphological differences that could affect their interaction with hydrodynamics and their survival capacity. $P$. oceanica leaves are longer and wider than C. nodosa leaves (Guidetti et al. 2002). These differences will affect the drag force exerted on the leaves and thus the anchoring requirements by the roots. Wicks et al. (2009) suggested that Zostera marina seedlings with the same root length but higher leaf area would have less chance to survive by being dislodged from the sediment than seedlings with lower leaf area. As $P$. oceanica has a higher total leaf surface area than C. nodosa (Guidetti et al. 2002), the drag experienced on the leaves will be higher in $P$. oceanica than in C. nodosa.

The objective of this work was to evaluate the capacity of seedlings of $P$. oceanica and $C$. nodosa to remain anchored to the substrata under different hydrodynamic conditions to get a fundamental understanding of seedling survival in nature. We studied the underlying mechanisms that can affect seedling survival in a biological flume. Drag measurements were carried out to obtain the effective drag forces acting on the seedlings and calculate the drag coefficient under unidirectional and oscillatory flows. Further, the dislodging depths and minimum root lengths necessary to remain anchored to the sediment were measured. Additionally, a replicated short-term field experiment was designed to compare the survival of 
seedlings at two depths (18 $\mathrm{m}$ and $12 \mathrm{~m}$ ) to assess the effect of exposure to hydrodynamics on the survival of $P$. oceanica and $C$. nodosa seedlings.

\section{Methods}

Posidonia oceanica and $C$. nodosa seedlings used in the flume and field studies were obtained from fruits collected at sea. P. oceanica fruits were collected from drift material on several beaches of Mallorca and Ibiza islands (western Mediterranean Sea) during April-May 2009. Fruits were manually opened and seeds were placed in natural-salinity seawater. Seed germination took place within a week or two after collection. C. nodosa seeds were collected during February-April 2009 in a shallow $(3 \mathrm{~m})$ meadow in Mallorca Island. Seeds were kept in aquariums until May 2009 , the month when $C$. nodosa seeds germinate at sea. Germination of $C$. nodosa was induced by reducing the salinity to 10 (Caye and Meinesz 1986). Both P. oceanica and $C$. nodosa germinated seeds were kept in aquariums with natural seawater during early seedling development. Aquariums were in a temperature-controlled room at $20^{\circ} \mathrm{C}$ with a 14-h photoperiod and a photon irradiance of $60 \mu \mathrm{mol} \mathrm{m} \mathrm{m}^{-2} \mathrm{~s}^{-1}$. Seedlings were haphazardly distributed into two groups, one for flume experiments and another for field experiments.

Drag forces and drag coefficient-Drag measurements were carried out to obtain the effective drag forces acting on individual seedlings and to calculate the drag coefficients of both species under unidirectional and oscillatory flows. Experiments were carried out in the Netherlands Institute of Ecology racetrack-shaped channel at Yerseke, the Netherlands. The channel is $17.55 \mathrm{~m}$ long, $0.6 \mathrm{~m}$ wide, and $0.45 \mathrm{~m}$ deep. In all experiments, water depth was $0.32 \mathrm{~m}$, water temperature was $20 \pm 0.5^{\circ} \mathrm{C}$, and salinity 36 . The flume allows running both unidirectional and oscillatory flows. Currents in the flume were generated by a conveyor belt. Waves were generated by a vertical wave maker driven by a piston. At the end of the test section waves were dampened by a porous gentle slope. Flow was characterized by measuring vertical profiles of the velocity at $5-\mathrm{cm}$ intervals along the water column using an acoustic Doppler velocimeter (ADV Vectrino, Nortek) at the same cross-section where seedlings were tested. The ADV sampling rate was $25 \mathrm{~Hz}$ and measurements were taken for $5 \mathrm{~min}$, sampling volume of $7 \mathrm{~mm}$, and a nominal velocity range of $1 \mathrm{~m} \mathrm{~s}^{-1}$.

Drag was measured on individual $P$. oceanica and $C$. nodosa seedlings fixed to a force transducer inside the flume. Seedlings were exposed to seven different wave conditions that include wave heights $(H)$ ranging from 1 to $7 \mathrm{~cm}$ and periods (T) from 1.5 to $4 \mathrm{~s}$. These waves gave near-bottom orbital velocities between 4 and $16 \mathrm{~cm} \mathrm{~s}^{-1}$. Seedlings were also exposed to six different current velocities ranging between 5 and $36 \mathrm{~cm} \mathrm{~s}^{-1}$. Hereafter, $u$ represents the near-bottom orbital velocity (for waves) or the mean velocity (currents). Each wave and current flow condition was repeated for five seedlings. Seedlings were attached to a 2 -cm-long metal screw by the stem using a small cable tie, removing the roots and seed. The metal screw was then fixed into the drag sensor. The drag force of the metal screw with cable ties alone is a constant, and was subtracted from the drag force measured on the seedlings. No breaking of leaves or plant fragments was observed during the drag experiments. Drag forces and wave heights were measured at $20 \mathrm{~Hz}$ during $3 \mathrm{~min}$. Drag forces were measured using a drag transducer developed by WL-Delft Hydraulics (Bouma et al. 2005) and calibrated as Stewart (2004). Waves were measured with a pressure sensor (Druck, PT1830). Drag measurements were performed on P. oceanica in October 2009 and February 2010, but drag in C. nodosa was only measured in October 2009 since seedlings did not survive until February 2010.

The force acting over individual plants measured by the transducer can be expressed as:

$$
F_{D}=\frac{1}{2} \rho C_{d} A u|u|
$$

where $\rho$ is the density of water, $A$ is the total leaf area of the plant, and $u$ the flow velocity (either unidirectional or oscillatory). The drag coefficient, $C_{d}$, which depends on the Reynolds number, can be readily obtained from the experiments using Eq. 1. Defining the characteristic length as (Martone and Denny 2008)

$$
l_{*}=\sqrt{A},
$$

the corresponding Reynolds number is defined as

$$
\operatorname{Re}=\frac{u l_{*}}{v},
$$

$v$ being the molecular kinematic viscosity of seawater. Most aquatic vegetation is flexible and becomes streamlined with increasing flow velocities and it is very difficult to measure accurately the frontal area under waves and currents (SandJensen 2003, 2005; but see Boller and Carrington 2007). For this reason, the total surface area was used as the frontal area as it can be accurately measured.

Critical erosion depth and minimum rooting length - Once the drag force was measured for the seedlings the next step was to analyze the capacity of both species to withstand dislodgement by sediment disturbances via root anchoring. Individual $P$. oceanica and $C$. nodosa seedlings were planted in cylindrical pots (height $\times$ diameter: $12 \times 12 \mathrm{~cm}$ ) over sand with a diameter $\left(d_{50}\right)$ of $592 \pm 23 \mu \mathrm{m}$. Pots were placed in the flume under two sets of experiments: periodic waves of $H=2.5 \mathrm{~cm}$ and $T=2.6 \mathrm{~s}\left(u=5 \mathrm{~cm} \mathrm{~s}^{-1}\right)$ and periodic waves of $H=5.1 \mathrm{~cm}$ and $T=1.9 \mathrm{~s}\left(u=10 \mathrm{~cm} \mathrm{~s}^{-1}\right)$ during 15 min (Fig. 1a). Seedlings were repeatedly exposed to $15 \mathrm{~min}$ of wave action, while in between wave treatments, sediment erosion was mimicked. This was repeated until we found the critical erosion depth at which seedlings dislodged (Fig. 1b). Sediment erosion was simulated by progressively adding discs of 3-mm thickness underneath the pots, removing carefully the pushed-up top layer of sediment. This process was repeated until the waves dislodged the seedling from the sediment. A total of 18 plants was used for $P$. oceanica and 9 for $C$. nodosa. For 


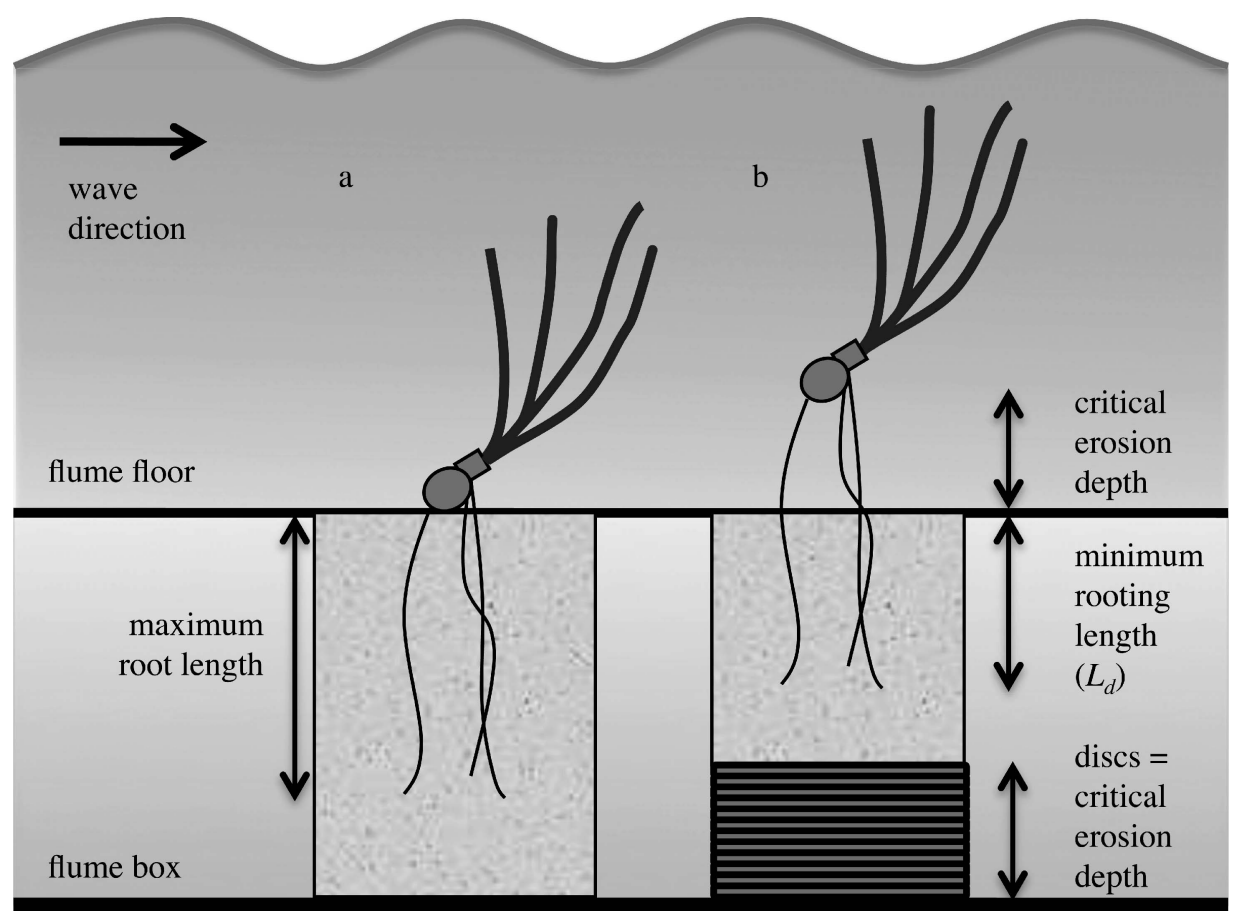

Fig. 1. Sketch of the flume experimental setup showing the critical erosion depth and minimum rooting length $\left(L_{d}\right)$ of seedlings. (a) Seedling in the flume, (b) seedling before dislodging from the sediment after the discs addition. Critical erosion depth is equivalent to the total height of discs added when the seedling is dislodged. Not drawn to scale.

each seedling, root lengths and total leaf area were measured. The critical erosion depth was measured as the thickness of disks added before the plant became dislodged. The minimum rooting length $\left(L_{d}\right)$ or length of the root inside the sediment before the plant became dislodged was obtained by the difference of the maximum root length and the critical erosion depth. The length of the longest root was used for all calculations since in the end, regardless of the number of roots, seedlings remained anchored to the substrata with only one root, even when the rest were dislodged.

Field study - Seedlings were planted at sea to assess their survival and to validate the principles observed in the flume. The field study was performed from August 2009 to February 2010 on Mallorca Island, Spain, western Mediterranean Sea (Fig. 2a,b). In this area, tides are almost negligible, e.g., less than $25 \mathrm{~cm}$. $P$. oceanica and $C$. nodosa seedlings were planted at two locations in the Natural Reserve of Cap de Enderrocat (Fig. 2c). The first location, Cap Enderrocat, is a sandy area between the upper depth limit of $P$. oceanica and the coastline exposed to southwest and southeast waves (triangles in Fig. 2c). The second location, Cala Blava, is located in a large $P$. oceanica meadow with sand gaps (circles in Fig. 2c), which is only exposed to southwest waves. The upper depth limit of $P$. oceanica in Cap Enderrocat is at $19 \mathrm{~m}$, whereas that in Cala Blava is at $12 \mathrm{~m}$. The upper depth limit of $C$. nodosa in Cap Enderrocat and Cala Blava is at $12 \mathrm{~m}$. Within each location two depths were selected, $18 \mathrm{~m}$ and $12 \mathrm{~m}$, for the short-term experiment.
Six plots (three for each species) separated by 3-m intervals were established at the four sites. Twelve seedlings were planted on each plot directly on the sediment without any artificial supporting aid, to mimic natural conditions where the roots are the only attachment structure to the substrata. A total of 144 seedlings of each species was planted after measuring the number of roots, root lengths, and root diameter in the laboratory. Additionally, the number of leaves of each seedling and the length and width of each leaf were measured once planted in the field. The number of seedlings in each plot was counted in September, October, and November 2009 and in February 2010. Whenever seedlings were no longer observed in the plots, we determined that the loss was not caused by burial.

Survival rate was related to wave conditions as well as to averaged near-bottom orbital velocities between sampling dates at the four experimental sites. Significant wave height $\left(H_{s}\right)$, peak period $\left(T_{p}\right)$, and direction $(\theta)$ were acquired at deep waters from a wave climate database, approximately $15 \mathrm{~km}$ from the study sites (Fig. $2 \mathrm{~b}$ ). These wave conditions were propagated to the study sites using a numerical model based on the mild-slope parabolic approximation (Kirby and Dalrymple 1983; Infantes et al. 2011). Wave conditions in the study area ranged between a $H_{s}$ of 0.5 and $4 \mathrm{~m}, T_{p}$ of 2 and $12 \mathrm{~s}$, and $\theta$ of 130 and $270^{\circ}$. Near-bottom orbital velocities at the four locations where $P$. oceanica and $C$. nodosa seedlings were transplanted were computed from the model output between sampling periods using linear wave theory (Dean and Dalrymple 1991). 


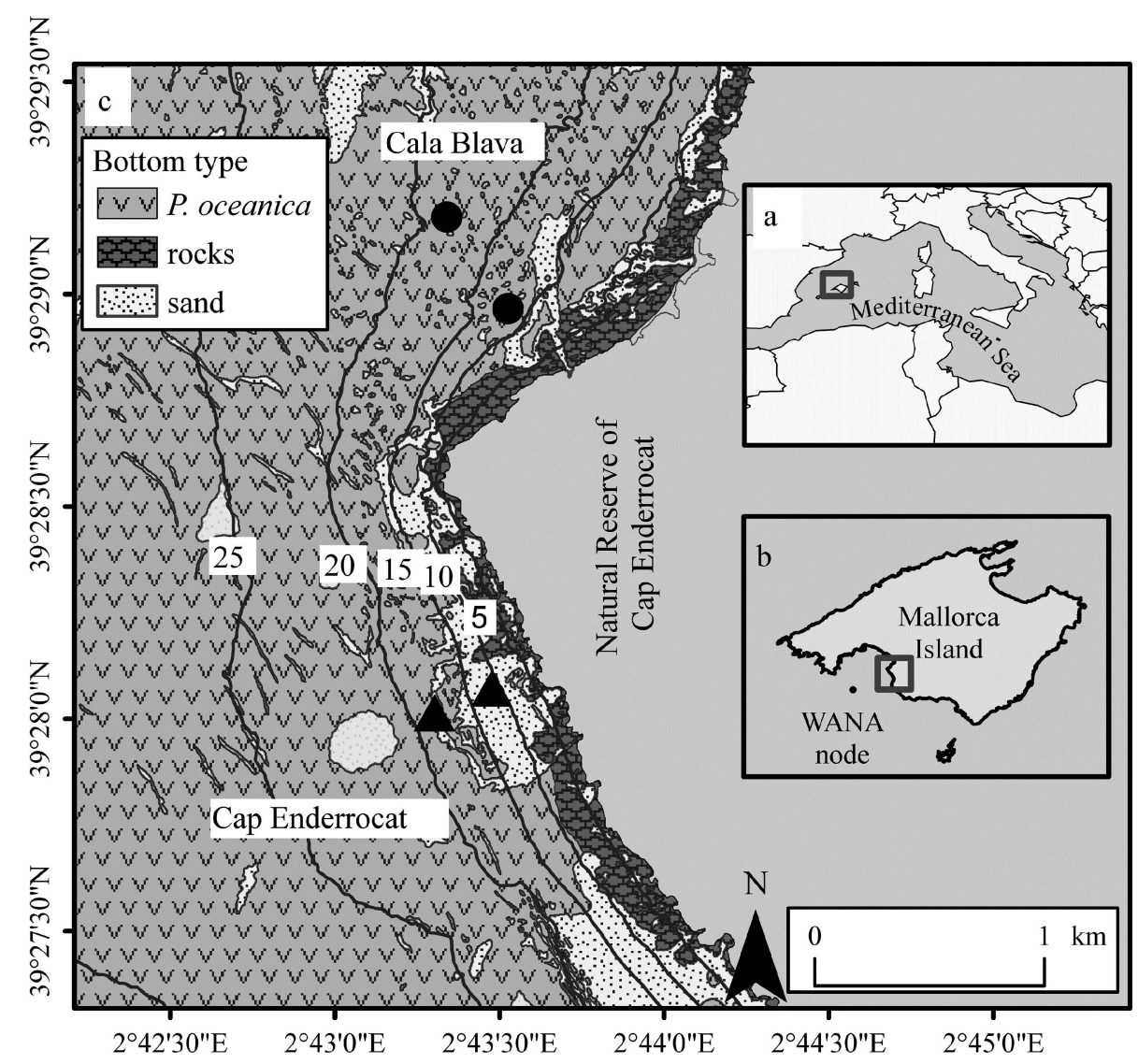

Fig. 2. (a) Location of Mallorca Island in the Mediterranean Sea. (b) Location of study area and deep-water wave climate data (WANA node). (c) Location of the experimental sites, Cap Enderrocat (triangles) and Cala Blava (circles). Bathymetric contours in meters.

Statistical analysis-Differences in drag forces under currents and waves of both species were tested using a Student's $t$-test. Differences among drag coefficients were evaluated using species ( $P$. oceanica, $C$. nodosa) and flow (unidirectional, oscillatory) as fixed factors and Reynolds number as the covariate in the analysis of covariance (ANCOVA) model $C_{d}=$ species + flow + Reynolds + (species $\times$ flow $)+$ (species $\times$ Reynolds) + (flow $\times$ Reynolds $)+$ (species $\times$ flow $\times$ Reynolds) (Quinn and Keough 2002). None of the two- or three-way interaction terms was significant in the ANCOVA, so only results for single-factor terms are reported here. Critical erosion depths and minimum rooting lengths in the sediment were evaluated using univariate test of significance, ANOVA. Wave velocity (orbital velocities of $5 \mathrm{~cm} \mathrm{~s}^{-1}$ and $10 \mathrm{~cm} \mathrm{~s}^{-1}$ ), species ( $P$. oceanica and $C$. nodosa) were the betweensubjects factors (fixed). Differences of seedling survivorship in the field experiment were also evaluated using univariate test of significance ANOVA. The test was performed only in October 2009 because we observed differences between sites on that date. After October 2009 no plants were left in most of the plots (see Results). Sites (Cap Enderrocat and Cala Blava), depth (18 m and $12 \mathrm{~m})$, species (P. oceanica and $C$. nodosa) were the factors (fixed). A Cochran's $C$-test was used to test for heterogeneity of variances. All data were normally distributed.

\section{Results}

Posidonia oceanica and C. nodosa have flexible leaves that easily bend with the currents or waves. Drag forces acting on individual seedlings increased with current and wave velocities (see Fig. 3). Drag forces also increased with foliar surface area for both sea grass species (Fig. 4). Drag forces were higher ( $t$-test: $t=7.08, \mathrm{df}=14, p<0.01$ ) for $P$. oceanica $\left(0.006 \pm 4 \times 10^{-4} \mathrm{~N}\right.$, mean $\left.\pm \mathrm{SE}\right)$ than for $C$. nodosa $\left(0.003 \pm 3 \times 10^{-4} \mathrm{~N}\right)$ at $u=16 \mathrm{~cm} \mathrm{~s}^{-1}$ in unidirectional flow (see Fig. 4). Similarly, drag forces were also higher ( $t$-test: $t=3.2, \mathrm{df}=14, p<0.01$ ) for $P$. oceanica $\left(0.011 \pm 1 \times 10^{-3} \mathrm{~N}\right)$ than for $C$. nodosa $(0.005 \pm$ $6 \times 10^{-4} \mathrm{~N}$ ) at $u=16 \mathrm{~cm} \mathrm{~s}^{-1}$ in oscillatory flow (see Fig. 4).

ANCOVA shows that drag coefficient $\left(C_{d}\right)$ depends on Reynolds number $(\mathrm{Re}),(F=298.7, \mathrm{df}=1, p<0.001)$ and that it is also influenced by the type of flow ( $C_{d}$ currents $>$ $C_{d}$ waves, $F=4.8$, df $=1, p<0.05$ ), but not by the species $(F=1.4, \mathrm{df}=1, p=0.24)$ (Fig. 5). A linear fitting of the drag coefficient for both species under oscillatory motion is:

$\log _{10} C_{d}=-0.6653 \cdot \log _{10} \operatorname{Re}+1.1886,\left(R^{2}=0.77, r=-0.87\right)$

and similarly for unidirectional flow: 

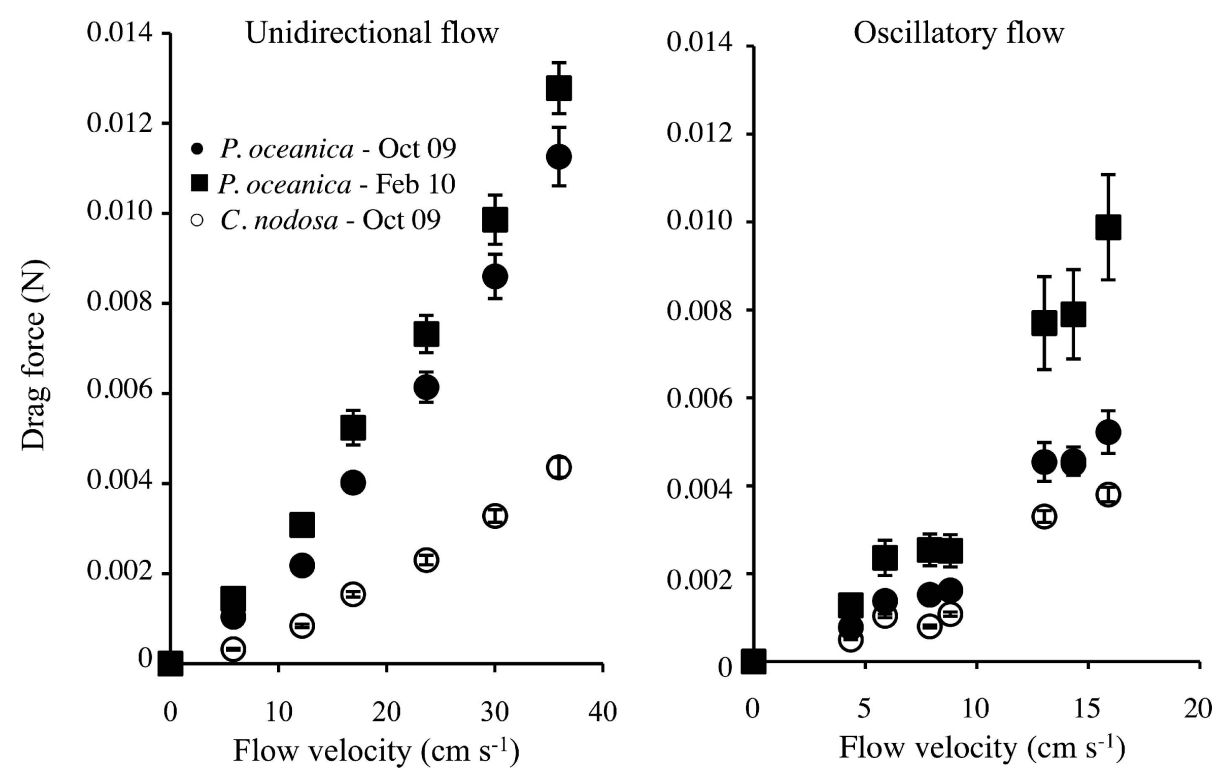

Fig. 3. Drag forces acting on seedlings in unidirectional flow and oscillatory flow (mean, SE, $n=5)$

$\log _{10} C_{d}=-0.7269 \cdot \log _{10} \operatorname{Re}+1.6253,\left(R^{2}=0.92, r=-0.95\right)$.

The experiments in the flume have shown that there are significant differences in the minimum rooting length that each species tolerates (Table 1). P. oceanica seedlings require $40-50 \%(2 \pm 0.2 \mathrm{~cm}$, mean $\pm \mathrm{SE})$ of root length anchored into the sediment, whereas $C$. nodosa requires only $20 \%(2.8$ $\pm 0.2 \mathrm{~cm}$, mean $\pm \mathrm{SE}$ ) of root length anchored into the sediment (Fig. 6). P. oceanica seedlings tolerate less sediment erosion $(2.7 \pm 0.3 \mathrm{~cm}$, mean $\pm \mathrm{SE})$ to become dislodged than $C$. nodosa $(5.6 \pm 0.4 \mathrm{~cm}$, mean $\pm \mathrm{SE})$ under waves.
The capacity of a plant to remain anchored depends on the force that the roots can manage (which mainly depends on their length $L_{d}$ ) and on the force that the exposed leaves receive from the ambient (which is highly dependent on the total leaf area $A$ ). The above suggests that an important dimensionless coefficient in the problem is the ratio $L_{d} / \sqrt{A}$. Since other variables could play a role in the problem, the ratio $L_{d} / \sqrt{A}$ will not be constant in general, and it could depend on other dimensionless groups representing the plant species, flow velocity, type of flow (wave or current), etc.

From the experimental results, only the influence of the species on $L_{d} / \sqrt{A}$ has been clearly identified as a measure
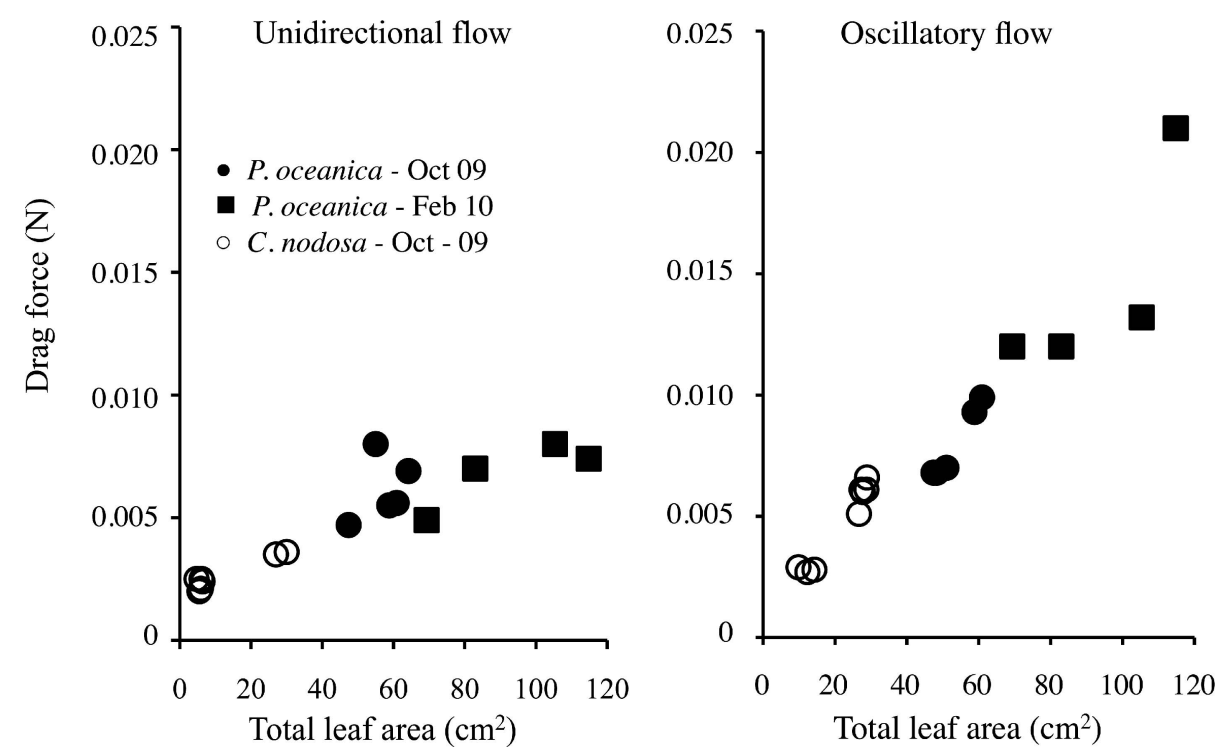

Fig. 4. Drag forces acting on individual seedlings of different surface area in unidirectional flow and oscillatory flow. Flow velocity of $16 \mathrm{~cm} \mathrm{~s}^{-1}$. 


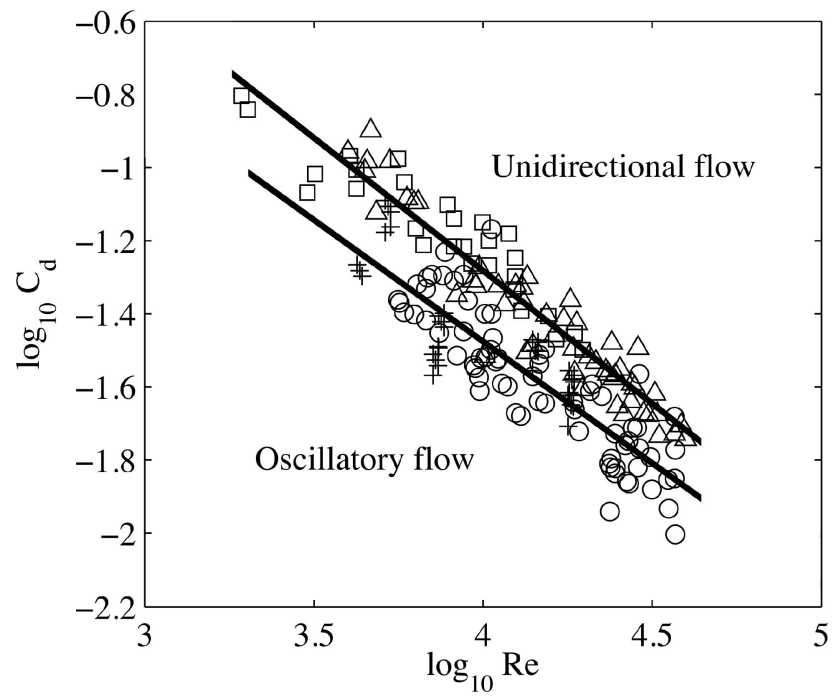

Fig. 5. Drag coefficient vs. Reynolds number for Posidonia oceanica and Cymodocea nodosa under unidirectional and oscillatory flow. Experimental data under unidirectional flow for $P$. oceanica seedlings (triangles) and for C. nodosa (squares). For oscillatory flow $P$. oceanica seedlings (circles) and $C$. nodosa (crosses). Solid lines are the linear fitting for the different flow conditions.

of the dislodgment risk, which can be termed as the dislodgement safety factor. Our results indicate that under periodic flows, seedlings of $P$. oceanica will remain anchored as long as $L_{d} / \sqrt{A} \approx 0.35$, i.e., if their root lengths are on average 0.35 times the square root of the leaves' area. In the case of $C$. nodosa the condition for the seedlings to remain anchored is $L_{d} / \sqrt{A} \approx 1.6$.

The foliar surface of $P$. oceanica seedlings at the beginning of the field experiment was four times larger than that of $C$. nodosa seedlings (Table 2). As seedlings develop, the difference in foliar surface increases. In contrast, $C$. nodosa maximum root lengths are higher than those of $P$. oceanica. Root diameters are higher for $P$. oceanica than for $C$. nodosa. Survival was related to wave conditions as well as to averaged near-bottom orbital velocities between sampling dates (Fig. 7; Table 3). No loss of seedlings occurred from August to September 2009. During this period no storms affected the study area and the computed near-bottom orbital velocities were below $5 \mathrm{~cm} \mathrm{~s}^{-1}$.

Between September and October 2009, a storm with $H_{s}$ of $1.5 \mathrm{~m}$ and $T_{p}$ of $7 \mathrm{~s}$ was measured at deep waters. During this period, the first losses of $P$. oceanica seedlings were observed. Computed $u$ for this period in Cap Enderrocat was $8.6 \mathrm{~cm} \mathrm{~s}^{-1}$

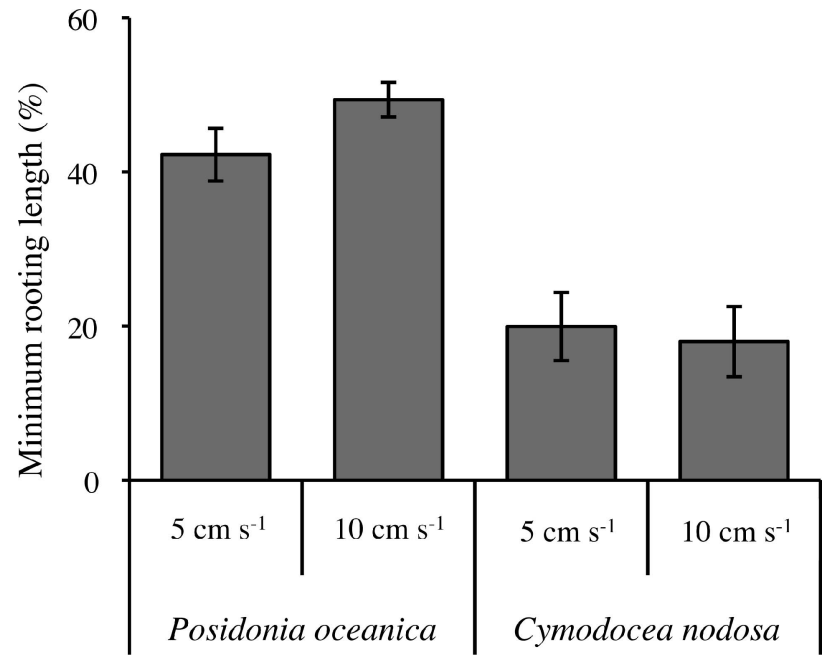

Fig. 6. Minimum rooting length of Posidonia oceanica and Cymodocea nodosa exposed to two orbital velocities $(u=5$ and $\left.10 \mathrm{~cm} \mathrm{~s}^{-1}\right)$.

at $18-\mathrm{m}$ depth and $28 \mathrm{~cm} \mathrm{~s}^{-1}$ at $12-\mathrm{m}$ depth, whereas in Cala Blava it was $7.3 \mathrm{~cm} \mathrm{~s}^{-1}$ at $18-\mathrm{m}$ depth and $14.7 \mathrm{~cm} \mathrm{~s}^{-1}$ at $12-$ $\mathrm{m}$ depth (Table 3). The percentage of $P$. oceanica seedlings surviving in Cala Blava was significantly higher than that in Cap Enderrocat (Fig. 7a; Table 4). Moreover, the percentage was significantly higher in the deeper $(18 \mathrm{~m})$ than in the shallow $(12 \mathrm{~m})$ sites. The loss for $C$. nodosa was also significant but no differences in the percentage of survivorship among sites and depths was detected.

From October to November 2009, two storms from the southwest with $H_{s}$ of 4 and $2.5 \mathrm{~m}$ and $T_{p}$ of 10 and $8 \mathrm{~s}$ respectively were recorded at deep waters. After these storms, all $P$. oceanica seedlings disappeared in both Cap Enderrocat and Cala Blava sites, whereas C. nodosa seedlings persisted in Cala Blava at both depths (Fig. 7b). Computed $u$ at the experimental sites varied between 17 and $34 \mathrm{~cm} \mathrm{~s}^{-1}$ (Table 3).

From November 2009 to February 2010 several storms were recorded with maximum $H_{s}$ of $5 \mathrm{~m}$ and $T_{p}$ of $11 \mathrm{~s}$ at deep waters (Fig. 7c). Remaining seedlings of $C$. nodosa persisted during this period. Computed $u$ in this site varied between 23 and $39 \mathrm{~cm} \mathrm{~s}^{-1}$ during that period of time.

\section{Discussion}

Present study offers a mechanistic insight into how the combination of drag and erosion may cause seedling

Table 1. Two-way ANOVA testing differences between species and orbital velocities and minimum rooting length. Significant differences are expressed in bold as $* * * p<0.001$, and ns, not significant. Cochran's $C$-test not significant. O.Velocities is orbital velocities. df, degrees of freedom; MS, mean square.

\begin{tabular}{|c|c|c|c|c|c|}
\hline & & df & MS & $F$ & $p$ \\
\hline \multirow{4}{*}{$\begin{array}{l}\text { Minimum rooting } \\
\text { length }\end{array}$} & Species & 1 & 6828 & 52.9 & $* * *$ \\
\hline & O.Velocities & 1 & 63 & 0.5 & ns \\
\hline & Species $\times$ O.Velocities & 1 & 196 & 1.5 & ns \\
\hline & Error & 34 & 129 & & \\
\hline
\end{tabular}


Table 2. Morphological characteristics of seedlings at the beginning of the field experiment (mean $\pm \mathrm{SE}, n=144$ ).

\begin{tabular}{lrc}
\hline \hline & $\begin{array}{c}\text { Posidonia } \\
\text { oceanica }\end{array}$ & $\begin{array}{c}\text { Cymodocea } \\
\text { nodosa }\end{array}$ \\
\hline Total foliar surface $\left(\mathrm{cm}^{2}\right)$ & $12.9 \pm 1.6$ & $3.21 \pm 0.4$ \\
Number of leaves & $6.1 \pm 0.6$ & $2.3 \pm 0.2$ \\
Number of roots & $5.2 \pm 0.2$ & $4.8 \pm 0.2$ \\
Total root length $(\mathrm{cm})$ & $15.8 \pm 0.2$ & $26.1 \pm 0.4$ \\
Max. root length $(\mathrm{cm})$ & $5.5 \pm 0.2$ & $6.8 \pm 0.4$ \\
Root diameter $(\mathrm{mm})$ & $1.78 \pm 0.1$ & $0.51 \pm 0.03$ \\
\hline
\end{tabular}

dislodgement from the substrata. Our results showed that drag forces were higher in $P$. oceanica seedlings than in $C$. nodosa under both current and waves, and that $P$. oceanica seedlings are dislodged earlier than $C$. nodosa seedlings. Thus flume results predict survival of $C$. nodosa seedlings to exceed that of $P$. oceanica seedlings. Field experiments confirmed this, by showing that seedlings were dislodged during storms, and that $C$. nodosa seedlings survived longer than $P$. oceanica.

Measured drag force per unit total leaf surface area is on average $\left(3 \pm 1.2 \mathrm{~N} \mathrm{~m}^{-2}\right.$ mean $\left.\pm \mathrm{SE}\right)$ for both the $P$. oceanica and $C$. nodosa seedlings at $u=16 \mathrm{~cm} \mathrm{~s}^{-1}$, which
Table 3. Computed near-bottom orbital velocities $\left(\mathrm{cm} \mathrm{s}^{-1}\right)$ at the experimental locations during the sampling periods (mean $\pm \mathrm{SD})$.

\begin{tabular}{lccccc}
\hline \hline & \multicolumn{2}{c}{ Cap Enderrocat } & & \multicolumn{2}{c}{ Cala Blava } \\
\cline { 2 - 3 } \cline { 5 - 6 } \cline { 5 - 6 } & $12 \mathrm{~m}$ & $18 \mathrm{~m}$ & & $12 \mathrm{~m}$ & $18 \mathrm{~m}$ \\
\hline Aug-Sep & $<5$ & $<5$ & & $<5$ & $<5$ \\
Sep-Oct & $18.0 \pm 1.1$ & $8.6 \pm 0.3$ & & $14.7 \pm 0.9$ & $7.3 \pm 0.2$ \\
Oct-Nov & $34.4 \pm 2.2$ & $18.2 \pm 1.2$ & & $29.4 \pm 1.9$ & $17.0 \pm 1.1$ \\
Nov-Feb & $46.0 \pm 2.3$ & $25.5 \pm 1.2$ & & $39.1 \pm 1.5$ & $23.4 \pm 1.1$ \\
\hline
\end{tabular}

was in the same order of magnitude as earlier measurements for sea grass model plants with flexible shoots (5.5$7.8 \mathrm{~N} \mathrm{~m}^{-2}$ ) at $37 \mathrm{~cm} \mathrm{~s}^{-1}$ (Bouma et al. 2005). For seedling survival, it is, however, the absolute drag force rather than the drag per unit surface area that matters. Present flume experiments show that drag coefficient $\left(C_{d}\right)$ depends on Reynolds number but not on the species and that this relationship is different for current and waves (Fig. 5). The computed drag coefficients for the individual seedlings of $P$. oceanica and C. nodosa are between 0.01 and 0.1 for Reynolds numbers between $10^{3}$ and $10^{5}$, which is in accordance with those provided for flexible macrophytes

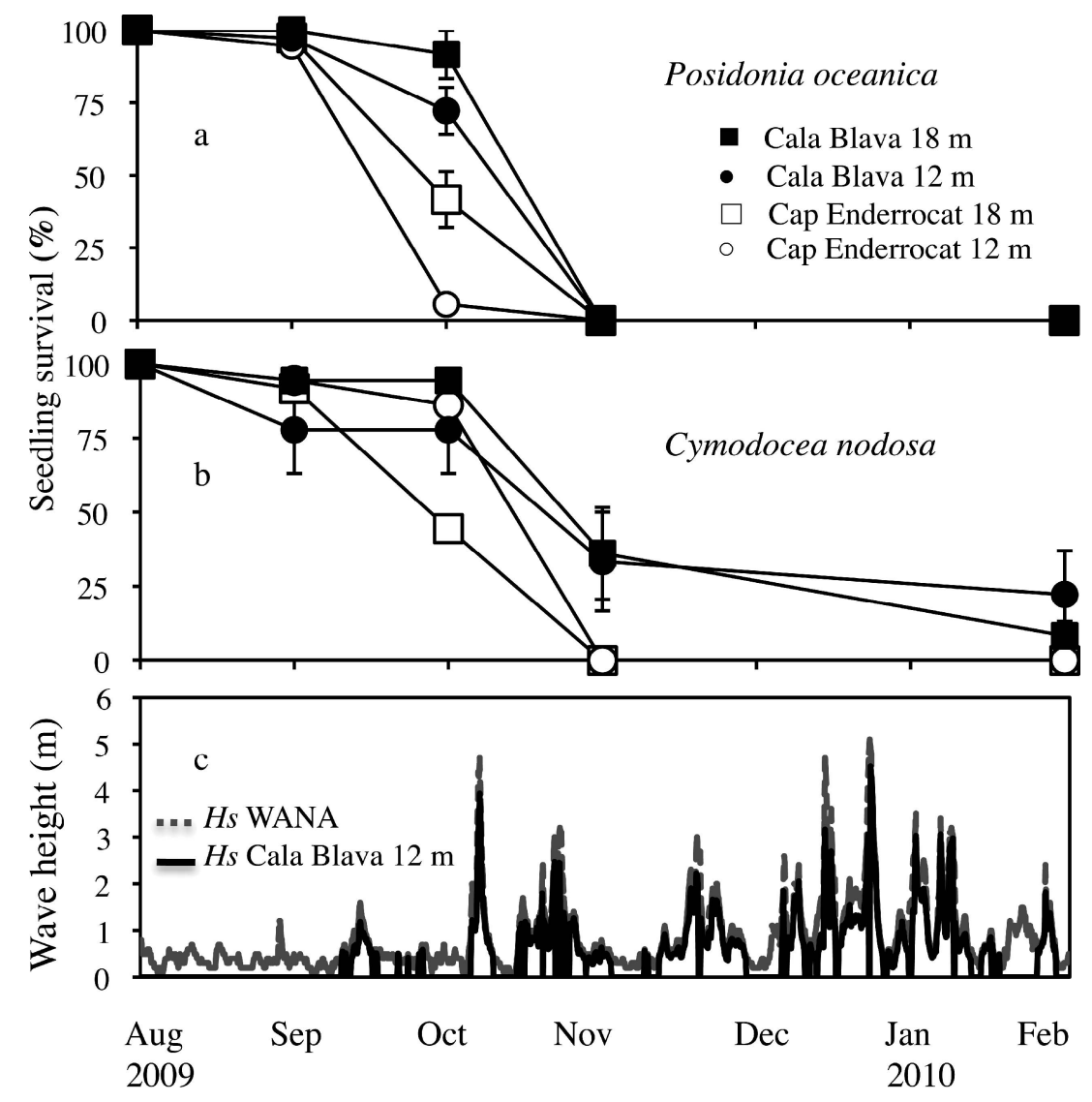

Fig. 7. Seedling survival on the experimental plots in Mallorca, August 2009 to February 2010. (a) Posidonia oceanica, (b) Cymodocea nodosa, and (c) wave heights in deep water (WANA node) shown in gray line and propagated wave heights in Cala Blava at 12-m depth shown in black line. Gaps in propagated $H_{\mathrm{s}}$ correspond to wave directions other than southwest to southeast not affecting the study area. 
Table 4. Results of three-way ANOVA of seedling survival percentage in October 2009. Significant differences are expressed in bold as: ${ }^{* *} p<0.01, * * * p<0.001$, and ns, not significant. Cochran's $C$-test not significant. df, degrees of freedom; MS, mean square.

\begin{tabular}{lrrrc}
\hline \hline & df & \multicolumn{1}{c}{ MS } & \multicolumn{1}{c}{$F$} & $p$ \\
\hline Location & 1 & $\mathbf{9 4 0 1 . 0 4}$ & $\mathbf{4 0 . 1}$ & $* * *$ \\
Depth & 1 & 350.12 & 1.5 & ns \\
Species & 1 & $\mathbf{3 1 5 1 . 0 4}$ & $\mathbf{1 3 . 5}$ & $* *$ \\
Location $\times$ depth & 1 & 651.04 & 2.8 & ns \\
Location $\times$ species & 1 & $\mathbf{2 1 0 9 . 3 7}$ & $\mathbf{9 . 1}$ & $* *$ \\
Depth $\times$ species & 1 & $\mathbf{2 4 3 3 . 4 5}$ & $\mathbf{1 0 . 3}$ & $* *$ \\
Location $\times$ depth $\times$ & & & & $* *$ \\
$\quad$ species & 1 & $\mathbf{2 1 0 9 . 3 7}$ & $\mathbf{9 . 2}$ & \\
Error & 16 & 234.38 & & \\
\hline
\end{tabular}

(Sand-Jensen 2003; Martone and Denny 2008). It should be noted that drag coefficients for meadows can depend on many factors such as the height and density of the plants, the distance traveled by waves, etc. and that drag coefficient for meadows thus may differ from the values presented for single plants.

Sediment mobilization is related to hydrodynamics (wave and currents), which can bury or dislodge sea grasses (Madsen et al. 2001; Cabaço et al. 2008). Previous studies have shown that $2 \mathrm{~cm}$ of sediment erosion caused $75 \%$ of mortality in C. nodosa seedlings in stagnant water (Marbà and Duarte 1994), but to our knowledge there are no data about the effect of sediment erosion on $P$. oceanica seedlings. In this study we show that $P$. oceanica seedlings under waves tolerate less sediment erosion $(2-3 \mathrm{~cm})$ to become dislodged than $C$. nodosa $(5-6 \mathrm{~cm})$. $P$. oceanica seedlings need a root length of 0.35 times the square root of the total leaf area to remain anchored, whereas in $C$. nodosa this condition is increased up to 1.6 times the square root of leaf area. However, seedlings of $P$. oceanica in the flume have a foliar area that is on average 20 times higher than those of $C$. nodosa and therefore the seedling capacity to remain anchored is much more limited for $P$. oceanica than for $C$. nodosa. This suggests that $P$. oceanica seedlings are adapted to grow at ambients less energetic than $C$. nodosa. This may also be inferred from the proportionally higher root biomass and lower leaf biomass that $C$. nodosa allocates compared with $P$. oceanica (Guidetti et al. 2002). Anderson et al. (2006) described the dislodgement of coenocytic green algae from soft sediments by waves measuring the mean force to dislodge the algae (4.9$12.7 \mathrm{~N}$ ), which increased as the leaf surface area increased.

The seedling survival in the field also showed that $P$. oceanica and $C$. nodosa seedlings behave differently under the same hydrodynamic conditions. C. nodosa seedlings survived longer than $P$. oceanica in Cala Blava during the field experiment. $P$. oceanica seedlings survived at a higher proportion in the deep than in the shallow sites at both locations during October 2009. In November 2009, all $P$. oceanica seedlings disappeared in the plots, whereas $C$. nodosa seedlings persisted at both depths in Cala Blava. Two storms took place before we observed the complete loss of $P$. oceanica seedlings in November 2009. We cannot determine which of these two events caused seedling loss but we can conclude that these storms had a deleterious effect on the survival of $P$. oceanica seedlings. The presence of a large $P$. oceanica meadow from the shallow areas to 30-35-m depths demonstrates that the sea grass is not light limited at the study site (Fig. 2c). Herbivory is not considered to be a cause of seedling loss because bite scars on the leaves were not observed. Different environmental conditions between sites associated with hydrodynamics such as sediment resuspension and turbidity could have an effect on the seedling survival, although these are indirect effects of wave exposure. Some studies have shown high mortality of seedlings in the field after storms. A mortality of $75 \%$ to $100 \%$ natural and transplanted $P$. oceanica seedlings on pebbles occurred during the first winter after planting, associated with storms (Balestri et al. 1998). Individual seedlings of four different Posidonia spp. planted in a blowout area did not succeed after 1 yr (Kirkman 1998).

Water depth had an effect on seedling survival: as waveinduced orbital velocities attenuate with depth, nearbottom orbital velocities will be higher at $12 \mathrm{~m}$ than at $18 \mathrm{~m}$. In October 2009, a significantly lower survival was observed for $P$. oceanica at $12 \mathrm{~m}$ than at $18 \mathrm{~m}$ (Fig. 7a; Table 4). Piazzi et al. (1999) observed lower survival rates of $P$. oceanica seedlings at $2-\mathrm{m}$ depth than at $10-\mathrm{m}$ depth. A correlative study in a $P$. oceanica meadow (Infantes et al. 2009) suggested that at depths between 0 and $5 \mathrm{~m}$ nearbottom orbital velocities were too high for $P$. oceanica to be present, whereas at depths greater than $7 \mathrm{~m}$ velocities were lower and a dense meadow was present.

Infantes et al. (2009) estimated a threshold in nearbottom orbital velocities of $38-42 \mathrm{~cm} \mathrm{~s}^{-1}$ for a $P$. oceanica meadow to be present in a shallow bay. In this study, $P$. oceanica seedlings had a $100 \%$ survivorship at near-bottom orbital velocities below $5 \mathrm{~cm} \mathrm{~s}^{-1}$, but for velocities between 7 and $18 \mathrm{~cm} \mathrm{~s}^{-1}$ the percentage of seedlings surviving decreased and all seedlings disappeared at velocities above $18 \mathrm{~cm} \mathrm{~s}^{-1}$. Some $C$. nodosa seedlings survived at velocities of $39 \mathrm{~cm} \mathrm{~s}^{-1}$. Thus, our results suggest that seedlings tolerate lower orbital velocities than mature plants. This is not surprising, because mature plants develop a network of roots and rhizomes that penetrate deeper into the substrata than seedlings. Other studies showed that transplanted $Z$. marina survived at orbital velocities of $40 \mathrm{~cm} \mathrm{~s}^{-1}$ but not at $60 \mathrm{~cm} \mathrm{~s}^{-1}$ (van Katwijk and Hermus 2000). For meadows, Cabaço et al. (2010) estimated that the decline of C. nodosa occurs at velocities over $60 \mathrm{~cm} \mathrm{~s}^{-1}$.

Flow velocity is an important factor determining the size of the marine organisms that inhabit benthic ecosystems (Denny et al. 1985). Present results suggest that the higher drag of large species may make small species relatively more successful in the colonization of exposed sites. This agrees with the convention (on the basis of size-related differences of growth rates) that large sea grass species generally occupy low-energy or sheltered habitats, whereas small sea grass species are able to colonize more energetic habitats because the capacity of small species to recover from disturbance through growth is higher that that of 
large species (Idestam-Almquist and Kautsky 1995; Blanchette 1997). Our results that seedlings of $C$. nodosa are able to persist under higher wave energies than those of $P$. oceanica are also in agreement with the old but untested assumption that $C$. nodosa is a pioneer species that stabilizes the substrata and facilitates the establishment of P. oceanica (Den Hartog 1970).

The findings presented in this paper provide the basis for understanding seedling survivorship of two Mediterranean sea grass species in sandy substratum under different hydrodynamic conditions. We have shown that morphological characteristics of each species such as foliar surface and root length are key factors in colonization processes. Moreover, drag and sediment erosion play an important role in seedling survival, a crucial stage of sea grass life. Habitat degradation and fragmentation caused by anthropogenic effects around the world's coastal zones raises the need to manage and restore sea grass beds (Orth et al. 2006). Seedling plantings could be more effective in sea grass restoration if more quantitative knowledge on the hydrodynamic effects that limit the survival of sea grass seedlings is gathered.

\section{Acknowledgments}

We thank Puertos del Estado for the wave climate data. We thank G. Samperio and M. Domínguez for field assistance and M. Luhar and H. Nepf for their comments on drag. Dirección General de Pesca (Govern de les Illes Balears) is thanked for granting permission to perform this study inside the Palma Bay marine reserve, and thanks also to Club Náutico S'Arenal, which kindly made available its harbor facilities to us.

E.I. acknowledges financial support from the Spanish Ministerio de Educación y Ciencia scholarship program (2006-12850). Research funds were provided by the Spanish Ministerio de Ciencia e Innovación (grants CIT-310000-2008-9 and CTM-201016915) and Ministerio de Medio Ambiente, Medio Rural y Medio Marino (grant 116/SGTB/2007/1.3).

\section{References}

Anderson, K., L. Close, R. E. DeWreede, B. J. Lynch, C. ORMOND, AND M. WALKer. 2006. Biomechanical properties and holdfast morphology of coenocytic algae (Halimedales, Chlorophyta) in Bocas del Toro, Panama. J. Exp. Mar. Biol. Ecol. 328: 155-167, doi:10.1016/j.jembe.2005.07.005

Balestri, E., L. Piazzi, And F. Cinelli. 1998. Survival and growth of transplanted and natural seedlings of Posidonia oceanica (L.) Delile in a damaged coastal area. J. Exp. Mar. Biol. Ecol. 228: 209-225, doi:10.1016/S0022-0981(98)00027-6

Blanchette, C. A. 1997. Size and survival of intertidal plants in response to wave action: A case study with Fucus gardneri. Ecology 78: 1563-1578.

Boller, M. L., And E. Carrington. 2007. Interspecific comparison of hydrodynamic performance and structural properties among intertidal macroalgae. J. Exp. Biol. 210: 1874-1884, doi:10.1242/jeb.02775

Boudouresque, C. F., G. Bernard, G. Pergent, A. Shili, and M. Verlaque. 2009. Regression of Mediterranean seagrasses caused by natural processes and anthropogenic disturbances and stress: A critical review. Bot. Mar. 52: 395-418, doi:10.1515/BOT.2009.057

Bouma, T. J., M. B. de Vries, E. Low, G. Peralta, C. Tanczos, J. van de Koppel, and P. M. J. Herman. 2005. Trade-offs related to ecosystem engineering: A case study on stiffness of emerging macrophytes. Ecology 86: 2187-2199, doi:10.1890/ 04-1588

Cabaço, S., O. Ferreira, and R. Santos. 2010. Population dynamics of the seagrass Cymodocea nodosa in Ria Formosa lagoon following inlet artificial relocation. Est. Coast. Shelf Sci. 87: 510-516, doi:10.1016/j.ecss.2010.02.002

- , R. Santos, and C. M. Duarte. 2008. The impact of sediment burial and erosion on seagrasses: A review. Est. Coast. Shelf Sci. 79: 354-366, doi:10.1016/j.ecss.2008.04.021

Caye, G., and A. Meinesz. 1986. Experimental study of seed germination in the seagrass Cymodocea nodosa. Aquat. Bot. 26: 79-87, doi:10.1016/0304-3770(86)90006-9

Costanza, R., And Others. 1997. The value of the world's ecosystem services and natural capital. Nature 387: 253-260, doi: $10.1038 / 387253 \mathrm{a} 0$

Dean, R. G., and R. A. Dalrymple. 1991. Water wave mechanics for engineers and scientist. Advanced series on ocean engineering, v. 2. World Scientific.

Den Hartog, C. 1970. The seagrasses of the world. North Holland.

Denny, M. W., T. L. Daniel, and M. A. R. Koehl. 1985. Mechanical limits to size in wave-swept organisms. Ecol. Monogr. 55: 69-102, doi:10.2307/1942526

Frederiksen, M., D. Krause-Jensen, M. Holmer, and J. S. LAURSEN. 2004. Spatial and temporal variation in eelgrass (Zostera marina) landscapes: Influence of physical setting. Aquat. Bot. 78: 147-165, doi:10.1016/j.aquabot.2003.10.003

Green, E. P., And F. T. Short. 2003. World atlas of seagrasses. Univ. of California Press.

Guidetti, P., M. Lorenti, M. C. Buia, and L. Mazzella. 2002. Temporal dynamics and biomass partitioning in three Adriatic seagrass species: Posidonia oceanica, Cymodocea nodosa, Zostera marina. Mar. Ecol. Pub. Staz. Zool. Napoli I 23: 51-67, doi:10.1046/j.1439-0485.2002.02722.x

Idestam-Almquist, J., And L. Kautsky. 1995. Plastic responses morphology of Potamogeton pectinatus L. to sediment and above-sediment conditions at two sites in the northern Baltic proper. Aquat. Bot. 52: 205-216, doi:10.1016/03043770(95)00499-8

Infantes, E., J. Terrados, and A. Orfila. 2011. Assessment of substratum effect on the distribution of two invasive Caulerpa (Chlorophyta) species. Est. Coast. Shelf Sci. 91: 434 441, doi:10.1016/j.ecss.2010.11.005

- B. Cañellas, and A. Alvarez-EllaCURIA. 2009. Wave energy and the upper depth limit distribution of Posidonia oceanica. Bot. Mar. 52: 419-427, doi:10.1515/BOT.2009.050

Kirby, J. T., And R. A. Dalrymple. 1983. A parabolic equation for the combined refraction-diffraction of Stokes waves by mildly varying topography. J. Fluid Mech. 136: 453-466, doi:10.1017/S0022112083002232

Kirkman, H. 1998. Pilot experiments on planting seedlings and small seagrass propagules in western Australia. Mar. Pollut. Bull. 37: 460-467, doi:10.1016/S0025-326X(99)00146-0

Kосн, E. W. 2001. Beyond light: Physical, geological, and geochemical parameters as possible submersed aquatic vegetation habitat requirements. Estuaries 24: 1-17, doi: $10.2307 / 1352808$

— AND OTHERS. 2009. Nonlinearity in ecosystem services: Temporal and spatial variability in coastal protection. Front. Ecol. Environ. 7: 29-37, doi:10.1890/080126

Madsen, J. D., P. A. Chambers, W. F. James, E. W. Koch, and D. F. Westlake. 2001. The interaction between water movement, sediment dynamics and submersed macrophytes. Hydrobiologia 444: 71-84, doi:10.1023/A:1017520800568 
Marbì, N., And C. M. Duarte. 1994. Growth response of the seagrass Cymodocea nodosa to experimental burial and erosion. Mar. Ecol. Prog. Ser. 107: 307-311, doi:10.3354/ meps 107307

Martone, P. T., And M. W. Denny. 2008. To break a coralline: Mechanical constraints on the size and survival of a waveswept seaweed. J. Exp. Biol 211: 3433-3441, doi:10.1242/ jeb.020495

Orth, R. J., AND OTHERs. 2006. A global crisis for seagrass ecosystems. Bioscience 56: 987-996, doi:10.1641/0006-3568 (2006)56[987:AGCFSE]2.0.CO;2

Piazzi, L., S. Acunto, And F. Cinelli. 1999. In situ survival and development of Posidonia oceanica (L.) Delile seedlings. Aquat. Bot. 63: 103-112, doi:10.1016/S0304-3770(98)00115-6

Quinn, G. P., And M. J. Keough. 2002. Experimental design and data analysis for biologists. Cambridge Univ. Press.

Rivers, D. O., G. A. Kendrick, And D. I. Walker. 2011. Microsites play an important role for seedling survival in the seagrass Amphibolis antarctica. J. Exp. Mar. Biol. Ecol. 40: 29-35, doi:10.1016/j.jembe.2011.03.005

SAnd-Jensen, K. 2003. Drag and reconfiguration of freshwater macrophytes. Freshw. Biol. 48: 271-283, doi:10.1046/j.1365-2427. 2003.00998.x

2005. Aquatic plants are open flexible structures - a reply to Sukhodolov. Freshw. Biol. 50: 196-198, doi:10.1111/j. 1365-2427.2004.01297.x
Short, F. T., R. C. Davis, B. S. Kopp, C. A. Short, and D. M. BuRDiCK. 2002. Site-selection model for optimal transplantation of eelgrass Zostera marina in the northeastern US. Mar. Ecol. Prog. Ser. 227: 253-267, doi:10.3354/meps 227253

Stewart, H. L. 2004. Hydrodynamic consequences of maintaining an upright posture by different magnitudes of stiffness and buoyancy in the tropical alga Turbinaria ornata. J. Marine Syst. 49: 157-167, doi:10.1016/j.jmarsys.2003.05.007

van Katwisk, M. M., and D. C. R. Hermus. 2000. Effects of water dynamics on Zostera marina: Transplantation experiments in the intertidal Dutch Wadden Sea. Mar. Ecol. Prog. Ser. 208: $107-118$, doi:10.3354/meps 208107

Wicks, E. C., E. W. Koсh, J. M. O’Neil, and K. Elliston. 2009. Effects of sediment organic content and hydrodynamic conditions on the growth and distribution of Zostera marina. Mar. Ecol. Prog. Ser. 378: 71-80, doi:10.3354/meps07885

Associate editor: Craig L. Stevens

Received: 11 January 2011

Accepted: 03 August 2011

Amended: 09 August 2011 